\title{
Una aproximación al panorama estratégico actual
}

Emilio Sánchez de Rojas Díaz*

\subsection{Introducción}

Si tuviéramos que escoger una palabra que definiera la situación global en la primera parte del siglo XXI, esa sería sin duda incertidumbre estratégica. Como nos recuerda Fareed Zakaria (2009, pp. 13-15) estamos viviendo el tercer gran cambio de la era moderna, el ascenso de los demás:

Un aspecto de esta nueva era es la traslación del poder de los estados a otros actores; y entre los «demás» que están ascendiendo, se incluyen muchos actores no estatales...El poder está abandonado los estados-nación para dirigirse hacia arriba, hacia abajo y hacia los márgenes.

Se está produciendo un cambio en el orden mundial, que se caracteriza por una redistribución "nodal" del poder (con nodos en EE.UU., UE, BRIC, etc.). A esta nueva distribución hay que añadir una mayor interdependencia entre los nodos (EE.UU. - China, o UE - Rusia). Esta interdependencia nodal se mantendrá probablemente en el sistema internacional durante las próximas décadas. Los intereses de las potencias -a

* Coronel de Artillería. Instituto Español de Estudios Estratégicos 
veces contrapuestos--, son indicadores fiables de las tendencias futuras que nos podrían llevar hacia la convergencia, la divergencia, o incluso hacia las luchas. Una discrepancia entre intereses globales compartidos e intereses particulares de cada "nodos" podría perturbar al gobierno global que se vería afectado negativamente. El mantenimiento simultáneo de un equilibrio inter-nodal y unos intereses nacionales requieren soluciones cooperativas, ya que los desequilibrios podrían afectar a muchos países.

Actualmente los límites entre la seguridad nacional y la internacional son dificiles de definir, apareciendo un concepto de amenaza, que se caracteriza por la ausencia de estas en la frontera y la ausencia de fronteras para la amenaza (Howard, 1987). La paradoja es que las denominadas "nuevas amenazas", como la inseguridad ciudadana, el terrorismo, la ciber-inseguridad, la proliferación nuclear, el tráfico de drogas, la piratería marítima, la inmigración ilegal, la contaminación ambiental y el cambio climático, la pérdida de identidad nacional que amenazan la paz y la estabilidad del mundo actual existen desde hace mucho tiempo, y se convierten en amenazas cuando son potenciadas por la globalización (Kourliansky, 2010).

Es difícil mantener una definición absoluta de la seguridad, como afirma Gérard Dussouy (2001), excepto a costa de simplificar la realidad de un contexto internacional en el que la amenaza ya no viene de un lugar o una fuente precisa, sino que es difusa. Frente a la concepción tradicional de seguridad aparecen formulaciones alternativas, como seguridad común, comprehensiva, cooperativa, global, etc. que cuestionaban el enfoque imperante (Pérez de Armiño, 2007) y facilitan la aparición de nuevos conceptos de seguridad como «seguridad societal» y «seguridad humana» que ilustra el cambio desde la primacía de la seguridad nacional (e internacional) hacia la seguridad transnacional, sub-nacional e individual (Hänggi, 2003, pp. 5-6).

Los problemas ya no tienen soluciones evidentes. El término «problemas perversos ${ }^{1} »$, se refiere a problemas que, no pueden ser descritos

1. En inglés "wicked problems". 
de una forma simple y estable, no pertenece a la clase de problemas que al ser tratados de una misma forma, se obtienen soluciones similares. En pocas palabras los problemas perversos son desordenados, descaminados y reactivos. Así, la falta de comprensión de las implicaciones estratégicas de una situación dada, produce situaciones mucho peores que la de partida que se pretendía mejorar (Watts, 2012, pp. 53-54). Este es el caso de la ley de las consecuencias imprevistas que ha afectado a Libia, Siria o Mali, o del efecto «globo», que se produce en la lucha contra el tráfico de drogas, particularmente cocaína.

Ninguno país, por poderoso que sea, puede hoy en día asegurar de forma unilateral su propia seguridad, estabilidad y prosperidad; ni siquiera EE.UU., que aun siendo la única superpotencia global, ha dejado de ser el poder hegemónico. El mundo debería tender hacia un orden multilateral que tuviera los valores como referencia, pero los marcos de referencia de estos valores pueden ser discrepantes. Las asunciones, las interpretaciones y los comportamientos de los diferentes modelos de cultura se basan en un conjunto de valores, que a menudo son distintos y que deben ser tenidos en cuenta.

La Real Academia de la Lengua define panorama como: 1) paisaje muy dilatado que se contempla desde un punto de observación y como 2) aspecto de conjunto de una cuestión, es decir, que nos referimos a una visión general contemplada desde un punto de vista. Otro significado es: 3) en los teatros, gran tela de superficie plana, de color uniforme o con pinturas, situada al fondo de la escena, que, adecuadamente iluminada, da la sensación del cielo natural o de amplitud ambiental, que nosotros sustituiremos por un mapa.

Podemos resumir que nuestro panorama estratégico, es decir, "de importancia decisiva para el desarrollo de algo" se ve influido por el punto de observación. No perciben de la misma forma una realidad determinada, una persona que se encuentra en la cumbre del Everest, que la que se encuentra en medio de una selva amazónica y al que la rama le tapa el árbol, el árbol le tapa el bosque y el bosque le tapa la montaña; no ven igual la misma realidad un europeo, un árabe, un chino, un pigmeo africano o un norteamericano del centro profundo. También se ve intuido por el marco de valores de referencia. Priorizando nuestros intereses o los 
enmarcados en nuestro sistema de valores, podemos influir y modificar la realidad.

El mapa de referencia: Los mapas se hace de manera intencionada con un centro y una periferia, y un arriba y un abajo. Por ejemplo, un mapa hecho por chinos tendrá a China en el centro, y en cambio, en un mapa realizado por europeos, España aparecerá como centro de gravedad del mundo.

\subsection{Los períodos históricos}

Se pueden definir diversos sistemas en la historia de los últimos siglos, comenzando con un primer periodo que iría desde la Paz de Westfalia (Tratados de Paz de Osnabrück, el 15 de mayo, y Münster, el 24 de octubre de 1648) hasta la Segunda Guerra Mundial caracterizada por el dominio de las naciones europeas que imponen sucesivamente sus imperios, siempre con una primera potencia imperial, pero no hegemónica. Es un periodo que se caracteriza por la inestabilidad y los conflictos frecuentes.

Una segunda fase - única en la historia- es la de la bipolaridad EUAURSS que se extiende desde la finalización de la Segunda Guerra Mundial 1945-1991, con dos bloques uno occidental y capitalista liderado por EE.UU. y otro oriental y comunista liderado por la URSS. La Guerra Fría fue un periodo de estabilidad armada: a pesar de los numerosos conflictos en la lucha por la independencia de las antiguas colonias, las dos superpotencias evitaban el conflicto directo; la confrontación era fundamentalmente ideológica (Cohen, 2011).

El fin de la Guerra Fría y la desaparición de la Unión Soviética dieron lugar a la desaparición de los principales mecanismos de estabilización, basados en los lazos estratégicos de la mayoría de los Estados en torno a las dos superpotencias. A partir del 11 de septiembre de 2001, y tras su corta etapa hegemónica EE.UU. define su nuevo enemigo, el terrorismo, y comienza sus acciones en Irak y Afganistán, demostrando su incapacidad de imponer sus intereses simultáneamente en dos conflictos regionales. 
En palabras del presidente Obama, en una sola generación, las revoluciones tecnológicas han trasformado nuestra manera de vivir, trabajar y hacer negocios... países como China e India se dieron cuenta de que, con algunos cambios, por su parte, podían competir con este nuevo mundo. De modo que empezaron a dar educación a sus niños desde antes y durante más tiempo y a hacer hincapié en las matemáticas y las ciencias... Estados Unidos sigue siendo la mayor economía, la más próspera del mundo: no hay ningún país con tantas empresas de éxito, ni que conceda más patentes a inventores y empresarios. Contamos con las mejores universidades del mundo, a las que vienen a formarse más estudiantes que a ningún otro lugar del mundo (Obama, 2011). Como dijo Robert Kennedy: "El futuro no es un regalo. Es una conquista":

Sostener el "sueño americano" no ha consistido nunca en quedarnos parados. Ha obligado a cada generación a sacrificarse, luchar, y hacer frente a las exigencias de una nueva era. Necesitamos innovar, educar y construir más que el resto del mundo. "El primer paso para conquistar el futuro es estimular la innovación en Estados Unidos" (Obama, 2011).

La Unión Europea ya era una superpotencia económica, y ahora lo es diplomática, pero aún no lo es militar; Brasil es el principal poder en Sudamérica, pero su declive económico, y la crisis política han reducido su influencia; India domina el sur de Asia; China y Japón -superpotencias económicas y militares-dominan el este de Asia; y en la parte occidental de Asia se produce un equilibrio inestable entre Irán, Arabia Saudita, Israel y una Turquía al alza, todo en ello con la presencia del autodenominado "Estado islámico" o "DAESH", y un conflicto sangriento que domina el panorama de Siria e Irak. Sudáfrica despunta como principal actor regional africano. Dejando aparte la región de Oriente Medio y norte de África, las mayores tensiones entre potencias se producen en el este de Asia, particularmente en la península de Corea y en el mar del Sur de China, que juega el mismo papel para China que el Caribe juega para EE.UU. (Cohen, 2011).

El papel de liderazgo de EE.UU. en el mundo, probablemente continuará, pero perdiendo poder en relación con otras potencias globales y regionales y con otros actores emergentes. El nuevo liderazgo norteamericano dependerá en gran medida de las opciones que tomen los electo- 
res, dado que la polarización dentro de los partidos clásicos, Demócrata y Republicano, es elevada y sus visiones sobre el futuro muy diferentes.

\subsection{Una visión sistemática}

Pero para comenzar pongamos un ojo de pez a nuestra "cámara virtual" y veamos al mundo como "sistemas". Esta representación del mundo nos mostraría los principales actores, las potencias mundiales. De esta visión podemos afirmar que la única superpotencia capaz de dominar aún todas las rutas comerciales marítimas es EE.UU., pero ya no esa potencia hegemónica del siglo XXI que anunciaba el presidente George W. Bush. Tras la debilidad puesta en evidencia por Al-Qaeda al atacar el corazón financiero del mundo, Nueva York, demostrando que la tierra corazón americana no estaba asegurada; y que la "ciudadela inexpugnable" fue atacada en su propio territorio, con sus propias armas -sus aviones- por personas formadas en su propio territorio y con un coste ínfimo. América ya no era la hegemónica, y el siglo americano se había quedado en una simple década, la que separa dos puntos de choque sistémicos: La desaparición de la Unión de Repúblicas Socialistas Soviéticas el 25 de diciembre de 1991 y los atentados en Nueva York y Washington el 11 de septiembre de 2001.

\subsection{1 ¿Qué es el poder?}

Define poder Nye (2002, pp. 1-2) como “...la capacidad de afectar los resultados como uno desea y, si fuera necesario, cambiar el comportamiento de los demás para hacer que esto ocurra". El poder blando es definible únicamente en relación con lo que no es, poder duro. El poder duro se identifica con los instrumentos militar y económico de la política. El poder blando sería por tanto la capacidad de alcanzar influencias por medios distintos de los militares y económicos:

Un país puede obtener los resultados que desea en la política mundial porque otros países -admirando sus valores, emulando su ejemplo, aspirando a su nivel de apertura y prosperidad- quieran seguirlo; se trataría de "cooptar a la gente en lugar de obligarlos"... Lo que es obvio, es que mientras que la aplicación del poder duro depende de la propia voluntad, la utilidad del poder blando, depende de que "el otro", nos admire y quiera emularnos; no asegura ningún resultado y supone tan 
solo una acción complementaria y no sustitutoria del poder duro (Nye, 2002, p. 5).

La aparición de lo que se ha venido a denominar como "Smart Power", combinación de poderes duros y blandos, no es sino el reconocimiento del enorme fracaso del poder blando, que tuvo su oportunidad en las primaveras árabes, y no solo no consiguió la emulación del modelo norteamericano, sino que promovió un profundo sentimiento antiamericano.

Stephen Walt, escritor de la escuela realista que desarrolló la teoría del Equilibrio de amenazas, argumentaba en su artículo "El mito del excepcionalismo americano", que los funcionarios y el ciudadano en general necesitan superar la concepción de que EE.UU. es una nación única, virtuosa y una fuerza del bien inevitable. Otros países observan con desconfianza a EE.UU., por su tradición de intervención en los asuntos internos de los demás, a veces para obtener tan solo unos escasos beneficios políticos, estratégicos o pecuniarios; sin hablar de su insistencia en mantener un dominio militar global perpetuo.

\subsubsection{El centro de gravedad}

Henry A. Kissinger afirmaba que "el centro de gravedad de los asuntos mundiales se está desplazando hacia el Pacífico, y prácticamente todos los actores principales en la escena internacional están definiendo sus nuevos papeles"... (2004).

El centro de gravedad militar se encuentra en el Pacífico; el centro de gravedad económico mundial (basado en los datos de PIB y en la situación geográfica de las ciudades más importantes del mundo) se desplaza de forma continua desde el Atlántico Norte hacia Asia; y el centro de gravedad de la población se encontraría "en el cruce de caminos entre China, India, Pakistán y Tayikistán”, en Afganistán.

El centro de gravedad estratégico estaría situado entre los puntos más críticos para el tráfico comercial marítimo, es decir, entre los estrechos de Ormuz y de Malaca. Si tuviéramos, por tanto, que situar el Centro de Gravedad de los asuntos mundiales estaría más cerca del Índico que del Pacífico, en lo que definió Kennan (1947) como "Rimland". 


\subsubsection{Los Estados Unidos de América}

En los primeros días de nuestra república, Estados Unidos tomó una decisión acerca de su relación con América Latina. El presidente James Monroe, que era también un ex secretario de Estado, declaró que Estados Unidos unilateralmente, y como hecho consumado, actuaría como protector de la región. La doctrina que lleva su nombre hacía valer su autoridad para intervenir y oponerse a la influencia de las potencias europeas en América Latina. Y a lo largo de la historia de nuestra nación [EE.UU.], los sucesivos presidentes han reforzado esta doctrina y tomado una decisión similar.

La doctrina Monroe sirvió de herramienta legitimadora durante el primer siglo de intervención de Estados Unidos en el exterior. Hasta la Primera Guerra Mundial, los intereses de política exterior de Estados Unidos se encontraban mayoritariamente en América Latina. La citada doctrina prevenía a los Estados europeos de intervenir en el continente americano. De ella se deriva la doctrina del "destino manifiesto", que se desarrolla a través de dos estrategias básicas:

- La exportación del modelo norteamericano.

- La exclusividad de acción de Estados Unidos en el continente (Sánchez de Rojas, 2016).

La visión actual de los intereses nacionales vitales de EE.UU. aparece en la Estrategia Nacional de Seguridad (Obama, 2010a), define cuatro intereses nacionales perdurables: Seguridad, Prosperidad, Valores y Orden internacional. Los intereses vitales (seguridad y prosperidad) se ven acompañados por unos valores y por la promoción de un orden internacional [iberal].

El cambio más dramático se ha producido en un momento en que Oriente Medio, Afganistán y China parecían monopolizar la política exterior norteamericana. En palabras del secretario de Estado, John Kerry (2013):

Hoy, sin embargo, hemos hecho una elección diferente. La era de la doctrina Monroe ha terminado. La relación que buscamos y que hemos trabajado mucho para fomentar no se trata de una declaración 
de los Estados Unidos acerca de cómo y cuándo va a intervenir en los asuntos de otros estados americanos. Se trata de todos nuestros países viéndose entre sí como iguales, compartiendo responsabilidades, la cooperación en cuestiones de seguridad, y no adherirse a la doctrina, sino a las decisiones que tomamos como socios para promover los valores y los intereses que compartimos.

Existen algunas constantes de la política norteamericana que han permanecido intactas a pesar del fin de la Guerra Fría (Sánchez de Rojas, 2016, p. 6). Para Blanco (1998, p. 164), la constante más significativa ha sido la permanencia de una perspectiva de «Guerra Fría» con respecto a Cuba (Sánchez de Rojas, 2016, p. 6). Este comportamiento no se explica por el potencial de amenaza que pudiera representar tras la desaparición de la Unión Soviética, sino por razones de índole interna en la política estadounidense, relacionadas con la cuestión migratoria y el lobby que mantienen en el Congreso los cubanos anticastristas residentes en los Estados Unidos (Sánchez de Rojas, 2016, p. 6).

El actual presidente, Donald Trump, tiene una posición diferente sobre América Latina, hasta el punto de que está empeñado en recuperar la grandeza de América, con una serie de iniciativas tendentes a devolver los puestos de trabajo al suelo norteamericano, mientras que el poder americano volvería a estar presente a lo largo y ancho del mundo. Dicha política afecta a América Latina en su conjunto, y aunque aún no ha delineado una política en relación con la mayoría de los países de América Latina, la generalización de sus opiniones sobre Méjico puede ser extrapolada al resto (Fuentes et. al, 2016).

Su política exterior se basa en la necesidad de construir un muro en la frontera sur de los Estados Unidos; su plataforma doméstica, a su vez, hace hincapié en los derechos de la Segunda Enmienda, las grandes reformas fiscales y políticas de inmigración hostiles. La hostilidad de Trump hacia los países de América Latina, específicamente México, vecino de Estados Unidos, sin duda, representaría un importante obstáculo para la prosperidad del continente si llegara a ganar la presidencia (Fuentes et. al, 2016). 


\subsubsection{China, India y Rusia}

Hoy, una nueva configuración de poderes está reformando el orden internacional. Un mundo de una superpotencia y muchas grandes potencias. El nacionalismo y la nación en sí misma lejos de haber sido debilitada por la globalización, ha retornado ahora para vengarse, el nacionalismo étnico ha retornado con fuerza, pero es más significativo el retorno del nacionalismo de las grandes potencias. En lugar de un nuevo orden mundial, los conflictos de intereses y ambiciones de las grandes potencias están produciendo de nuevo alianzas y contra alianzas, y un elaborado cambio de parejas de baile, que cualquier diplomático del siglo XI reconocería de forma instantánea (Chen, 2003, p. 287).

Junto con EE.UU. aparecen en nuestro estudio sistémico tres potencias -que los expertos denominan emergentes- China, India y Rusia. La Unión Europea muestra su incapacidad de influir por su debilidad política y su no disponibilidad de una fuerza militar - a pesar de que la suma de sus países socios sea impresionante-- Iberoamérica aparece como irrelevante y África como inexistente. Pero no hay que olvidar que -como ocurre con una fotografía tomada con un objetivo de ojo de pez- es una imagen deformada, por lo que tendremos que acercarla progresivamente con nuestro "zoom estratégico".

Estos "jugadores" de partidas estratégicas, particularmente China e India, tienen una dependencia crítica de los hidrocarburos para poder mantener su crecimiento económico, por lo que deben asegurar las rutas de abastecimiento, que incluyen puntos estratégicos de paso obligado, como los estrechos de Ormuz y de Malaca. Esto ha dado lugar a unas geo-estrategias de "cerco" y "contra cerco" entre Estados Unidos, China, India y Rusia. El "tablero" principal de esta partida de ajedrez se encuentra en la periferia de Euroasia (Rogers, 2009) y el "núcleo duro" de la competición geopolítica mundial, al menos a corto plazo, estará compuesto por los Estados Unidos, China y Rusia. Tres Estados continentales que poseen un cuarto de la superficie de la tierra y más de un tercio de la población mundial (Fiori, 2011).

El estrecho de Malaca es uno de los pasos de mayor importancia estratégica del mundo con un tráfico anual de más de 60.000 barcos, 
transportando la mitad del petróleo del mundo y un 90\% del petróleo importado por China, Japón y Corea del Sur, el segundo, cuarto y séptimo socios comerciales de Estados Unidos, respectivamente (Commander U.S. Pacific Command Before The Senate Armed Services Committe on U.S.). Es en este ambiente en el que, durante la era Bush, si bien Estados Unidos mantuvo su primacía global, mostró sus propias limitaciones, al no poder proyectarse simultáneamente en múltiples escenarios y tener que priorizar sus esfuerzos, que se centraron en mantener su "Gran Barrera", definida por sus bases avanzadas entre Corea del Sur, Japón, Taiwán y el rosario de islas que van desde San Diego a Hawái y a la isla de Guam, y en el reforzamiento de las relaciones con India (Rogers, 2009). El mantenimiento de esta estrategia de contención y control de Estados Unidos contra China y en menor medida contra Rusia, se basa en la capacidad de refuerzo mutuo entre las costas Este y Oeste, siendo el canal de Panamá un elemento estratégico vital para Estados Unidos.

El cumplimiento de nuestro destino manifiesto es extendernos por todo el continente que nos ha sido asignado por la Providencia para el desarrollo del gran experimento de libertad y autogobierno. Es un derecho como el que tiene un árbol de obtener el aire y la tierra necesarios para el desarrollo pleno de sus capacidades y el crecimiento que tiene como destino (O’Sullivan, 1845b). Y esta demanda está basada en el derecho de nuestro destino manifiesto a poseer todo el continente que nos ha dado la providencia para desarrollar nuestro gran cometido de libertad, y autogobierno (O’Sullivan, 1845a).

La doctrina del destino manifiesto, que aún defiende la percepción de liderazgo histórico que tiene la nación americana, se basa en la exportación del modelo norteamericano y la exclusividad de acción de los EE.UU. en el denominado Continente Occidental. En cuanto a los intereses americanos, Mahan (1980), en su libro The influence of sea power upon history decía que:

El interés nacional de los Estados Unidos en el mundo, por encima de ideologías, será asentar y exportar su modelo político, fruto de nuestros principios de libertad, por nuestro natural continente, especialmente en los territorios más cercanos, preservándole a este de nocivas y caducas injerencias... 
La conocida como doctrina Kennan (1947), sitúa los intereses norteamericanos en lograr sus objetivos por medio de una política de poder guiada por el interés nacional que ha sobrevivido durante más de 50 años, hasta finales del siglo XX.

La visión actual de los intereses nacionales vitales de EE.UU. aparece en la Estrategia Nacional de Seguridad, define cuatro intereses nacionales perdurables: Seguridad, Prosperidad, Valores y Orden Internacional (Obama, 2010a). Los intereses vitales (Seguridad y Prosperidad) se ven acompañados por unos valores y por la promoción de un orden internacional [liberal].

\subsubsection{Relaciones EE.UU.-Potencias emergentes: Lo que permanece y lo que ha cambiado}

Lo que no ha cambiado, decía Condoleezza Rice, es que nuestras relaciones con las grandes potencias tradicionales y emergentes aún son importantes para la exitosa conducción de la política. Así, mi advertencia del año 2000 de que debíamos intentar mejorar las "relaciones con las grandes potencias" - Rusia, China y potencias emergentes como India y Brasil- nos ha guiado de manera consistente. Como antes, nuestras alianzas en las Américas, Europa y Asia siguen siendo los pilares del orden internacional y ahora estamos transformándolas para enfrentarnos a los retos de una nueva era. ... Por necesidad, nuestras relaciones con Rusia y China se han basado más en intereses comunes que en valores compartidos y se caracterizan tanto por la competencia como por la cooperación (Rice, 2008, p. 130).

Al priorizar el Pacífico Norte se abandonaron otros espacios geopolíticos de menor riesgo (al menos en teoría), particularmente Europa -donde ejerce su influencia a través de la OTAN- y América Latina, donde se ha centrado en contrarrestar las amenazas representadas por el terrorismo, la migración ilegal y la delincuencia transnacional organizada, particularmente la relacionada con el tráfico de drogas. Esta retirada estratégica ha supuesto una pérdida de influencia en Oriente Medio, y una reducción del liderazgo percibido de Estados Unidos.

Lo que ha cambiado es, como señala Condoleezza Rice (2008, pp.130-131), a muy grandes rasgos, la manera como vemos la relación 
entre la dinámica interna de los Estados y la distribución de poder entre ellos. Conforme la globalización fortalece a algunos países, también expone y exacerba las deficiencias de muchos otros, como los que son demasiado pobres o están mal gobernados como para poder resolver los problemas dentro de sus fronteras y evitar que estos se esparzan y desestabilicen el orden internacional...Esta nueva realidad nos ha obligado a hacer importantes cambios en nuestra política. Reconocemos que la construcción de Estados democráticos es ahora un componente apremiante de nuestro interés nacional (Rice, 2008).

La importancia de mantener relaciones sólidas con los actores globales se extiende especialmente con Brasil y con la India, afirma Rice, "tenemos un interés vital en el éxito y la prosperidad de éstas y otras grandes democracias multiétnicas de alcance global como Indonesia y Sudáfrica". Y en tanto que cambia el escenario geopolítico, las instituciones también deberán cambiar para reflejar esta realidad. Por esa razón, "el presidente Bush ha dejado claro su apoyo a una ampliación razonable del Consejo de Seguridad de la ONU” (Rice, 2008).

\subsubsection{Falta de liderazgo global}

No es que Estados Unidos no tenga capacidad de liderazgo global, sino que le falta voluntad...los estadounidenses debemos participar en la política exterior porque lo tenemos que hacer y no porque lo deseemos (Rice, 2008).

Y en palabras del presidente Obama (2010b):

Una y otra vez, los americanos se han levantado para enfrentarse e influir, en los momentos de cambio. Este es uno de esos momentos - una era de transformación económica y potenciación de lo individual; de odios ancestrales y nuevos peligros; de potencias emergentes y nuevos desafios globales.

Lo cierto es que el nivel de incertidumbre parece indicar que nos encontramos ante un periodo de falta de liderazgo global, para algunos, tras la decadencia del liderazgo norteamericano, materializado por sus intervenciones poco decisivas en las guerras de Irak y Afganistán y por el fracaso a la hora de afrontar la crisis de Libia, donde la solución ha 
resultado peor que el problema, o en Siria donde la falta de liderazgo ha permitido la emergencia de un nuevo actor global DAESH, que ha dado igualmente lugar a una situación mucho peor que la que se pretendía solucionar. Probablemente a EE.UU. le sucederá de nuevo EE.UU., pero con una forma de liderazgo diferente, más centrada en el interior -American First- y menos preocupada por extender los valores de su democracia liberal por todo el mundo.

\subsubsection{Competición estratégica. América, China y los otros "ladrillos"}

Un concepto del que parece obligado hablar es de BRICKS, o los nuevos "ladrillos" del mudo multi-nodal. El termino original BRIC (Brasil, Rusia, India, China), es puramente económico viene de la tesis propuesta por Jim O'Neill - economista global en Goldman Sachs-en octubre de 2003, a los que se han sumado Corea del Sur y Sudáfrica. Este grupo de países superarían al G6 (EE.UU., Japón, Alemania, Francia, Italia y Reino Unido) entre 2030 y 2040. La realidad es que se ha exagerado el papel de este grupo con pretensiones de competir geopolíticamente con los EE.UU. A pesar del declive Americano, los BRICKS no son más que tres potencias nucleares China, India, y Rusia - estos dos últimos a su vez competidores estratégicos de China- a los que se suman dos "palmeros", Brasil y Sudáfrica que tan solo aportan un toque exótico. En las últimas crisis - particularmente las de Libia y Siria- han mostrado los límites de su influencia real. Son sin duda potencias globales pero no superpotencias, solo EE.UU. merece, a día de hoy, ese calificativo.

\subsubsection{El terrorismo global}

Sobre el terrorismo Global opinaba el Presidente Obama (2011) que:

Mientras estamos hablando, Al-Qaeda y sus afiliados continúan planeando ataques contra nosotros. Gracias a nuestra inteligencia y profesionales de los servicios de seguridad, se están frustrando planes terroristas y se están asegurando nuestras ciudades y cielos.

La eliminación en Pakistán de Osama Bin Laden no implica necesariamente la desarticulación del terrorismo global salafista-yihadista, pero el 
poder se ha transferido desde Al-Qaeda central a sus grupos afiliados, produciéndose una regionalización y la aparición de varios centros de gravedad terrorista, indicador de la descomposición de la organización terrorista. Uno de esos centros de gravedad se encuentra en los países del Sahel y ha afectado ya a los intereses vitales de España, al ser capturados varios ciudadanos españoles - los últimos muy recientemente en los campos de Refugiados saharauis de Tinduf-- por Al-Qaeda del Magreb Islámico y exigir rescate por ellos.

Los que estaban interesados en una agenda nacional o local, en raras ocasiones se interesaban por la violencia transnacional, mientras que los que tiene ambiciones internacionales de orientación global, están muy distanciados de una base amplia de apoyo local. La aproximación en tres frentes a la Yihad era ambiciosa y demostró su capacidad al atacar a los EE.UU., pero posteriormente se vio incapaz de controlar estratégicamente a los grupos indígenas (Koehler-Derrick, 2011).

Tras la decadencia en Al Qaeda se ha producido un cambio importante en la forma de operar de muchos grupos terroristas salafistas yihadistas. La violencia extrema, la estrategia en tres frentes diferentes, la ocupación y control del terreno y la explotación local como medio de financiación, junto con la explotación de la propaganda, especialmente en las redes sociales son algunos aspectos que han cambiado. Parece como si fuera un fenómeno nuevo que aterroriza a la comunidad internacional, dando lugar a situaciones que rayan el pánico institucional. Algunos expertos recuerdan el terrorismo practicado por grupos como Al-Gama'a Al-Islamiyya en Egipto o al sanguinario GIA en Argelia en cuanto a la forma de emplear el terrorismo. Como ocurre hoy con el califato de DAESH, estos grupos trataron en su momento de crear emiratos que controlaran territorios donde imponer la ley islámica, aplicando la hisba (ordenar el bien y prohibir el mal).

La hibridación entre grupos terroristas y grupos de delincuencia transnacional organizada es un aspecto emergente. Ciertos grupos terroristas -como las FARC, o Hezbollah- emplean diversas actividades delictivas para financiarse, mientras que grupos de delincuencia transnacional organizada - como los Zeta o el cartel de Sinaloa- emplean el terror para imponer un control territorial. Los límites se han difuminado 
y las actividades se solapan. La pregunta fundamental: ¿nos encontramos ante una nueva oleada -la quinta- del terrorismo internacional?

Brian Jenkins, director del programa de Seguridad y Conflicto Subnacional de la $R A N D$ Corporation, en una entrevista concedida en 1988 afirma lo siguiente «los terroristas prefieren mucha gente observando atentamente a mucha gente muerta» ${ }^{2}$, subrayando el fuerte carácter comunicativo de la violencia terrorista y la existencia de una tendencia en el sentido más amplio (Ranstorp, 2006, p. 7). James Woolsey, exjefe de la CIA afirmaba en 1994. Algo ha cambiado, "los terroristas de hoy no quieren un lugar en la mesa, lo que quieren es destruir la mesa y a todo el mundo que se sienta en ella" (Lemann, 2001).

¿Nos encontraríamos a las puertas de una nueva oleada como sugiere Rapapport? (2002). Algunos elementos parecen confirmarlo y la decadencia de Al-Qaeda se ha visto solapada por la creciente influencia de DAESH. Este tiene tres componentes o personalidades diferentes: como un proto-Estado controla territorios cuyas fronteras son difusas y que define como Estado islámico con unos espacios de control duro y otros de control más tenue. DAESH es también una red de redes de grupos radicales que operan en el mundo musulmán y fuera de él. DAESH es también un estado mental que inspira a jóvenes extranjeros con profundos problemas sociales.

DAESH es un ejemplo paradigmático de los nuevos grupos terroristas. DAESH tiene una estrategia basada en tres niveles y su organización se adapta a cada uno de ellos. El primer nivel estratégico es el que incluye la zona donde trata de imponer su califato: Siria, Irak, Líbano, Jordania donde trata de ocupar y controlar el territorio para explotarlo y que sirva de base para futuras aventuras. Su forma de actuación recuerda al de los grupos regulares o los grupos insurgentes que empleaban el terrorismo como herramienta para alcanzar un objetivo político. Igualmente es la base de financiación del conjunto.

En un segundo nivel apoya a grupos, en su mayoría, anteriormente ligados a Al-Qaeda, y que le han rendido pleitesía; estos grupos actúan

2. http://www.lib.uci.edu/quest/index.php?page=jenkins 
en el resto del mundo árabe no incluidos en el primer nivel. Tras entrenar y armar a estos grupos, los reactiva cuando el frente interno ha sufrido reveses importantes para demostrar su alcance y capacidad. Es la principal fuente de reclutamiento para sustituir al número creciente de bajas que sufre.

En un tercer nivel estratégico está el resto del mundo, donde hay presencia minoritaria musulmana. La propaganda y las redes sociales están produciendo un efecto llamada y una autoradicalización de una población musulmana de segunda o tercera generación, desconectada de su país de origen y desafectada de su país de residencia. Es una fuente de reclutamiento de unos jóvenes, que de sobrevivir al conflicto, retornaran híper-radicalizados: este es el principal problema occidental.

\subsubsection{Del fracaso de Irak al de Afganistán}

Tendremos que derrotar a determinados enemigos allá donde se encuentren, y construir coaliciones, decía Obama (2011), "Mira a Irak, donde cerca de 100.000 de nuestros bravos hombres y mujeres han salido con las cabezas bien altas, la violencia se ha reducido, y se ha establecido un nuevo gobierno". La guerra de Irak había llegado aparentemente a su fin y, narrativas aparte, se ha convertido en un enorme fracaso, con unas consecuencias no previstas que superan incluso al peor escenario, Libia.

Pero es el fracaso en Afganistán, que recuerda el de la Unión Soviética, el más significativo. "Nuestras tropas han tomado zonas fuertes talibanes y entrenado a las Fuerzas de Seguridad Afganas" afirma Obama "previniendo el re-establecimiento del dominio Talibán sobre el pueblo de Afganistán, impidiendo el uso por parte del santuario que sirvió de rampa de lanzamiento para el 11 de septiembre". Quedan luchas difíciles y el Gobierno afgano tendrá que mejorar su gobernanza... Este julio [2011] comenzaremos la repatriación de nuestras tropas. De nuevo la descripción adornada de la impotencia, el reloj sigue corriendo para occidente, pero el tiempo corre a favor de los talibanes. Al-Qaeda no es un enemigo imaginario, pero la invasión y destrucción de Afganistán como respuesta al terrorismo, está preñada de dudas legales y morales. Tras casi una década todos quieren salir de una guerra difícil de justificar. 
El fracaso está confirmado. Una década de inversión en seguridad, de apoyo al desarrollo y de ayuda humanitaria y más de cuarenta billones de euros gastados entre 2002 y 2010, sin contar el dinero invertido en la guerra, no han sido suficientes para hacer de Afganistán un país políticamente estable y económicamente viable. Las instituciones del Estado permanecen frágiles, incapaces de asegurar una buena gobernanza ante la pérdida de credibilidad, la corrupción y el nepotismo que gangrenan al régimen del presidente Hamid Karzai. "El 80\% de la ayuda no va a manos del Estado afgano ni pasa por las instituciones del país, que necesitan ser reforzadas en su legitimidad" (Desoulieres, 2011).

Para Robert Gate la estrategia de los Estados Unidos estaría ahora dirigida a asegurar el acceso a los Global Commons, renunciando a dos de las herramientas que han permitido mantener su hegemonía durante casi dos décadas: "el derrocamiento de regímenes hostiles y las operaciones de paz en Estados fallidos" (Frías, 2011). Al renunciar al despliegue de grandes contingentes expedicionarios lo hace a operaciones como las de Irak, Afganistán, o Siria. Los europeos tendremos que decidir a partir de ahora -ya se ha experimentado en Libia-, si estas operaciones de cambio de régimen responden a nuestros propios intereses y si son realizables con nuestras propias capacidades.

El problema es que el marco de referencia con el que los europeos interpretamos la realidad internacional no coincide de hecho con los de países como Rusia y China, que disponen de veto en el Consejo de Seguridad de ONU, ni siquiera, en algunos casos, con el de los EUA (Pontijas, 2011). ¿Podría la Unión Europea, fortalecida por el Tratado de Lisboa, gozar de la legitimidad necesaria para articular un mensaje político sin ambigüedad?, y así evitar una transferencia de responsabilidades precipitada en Afganistán. En mi opinión, no.

\subsection{Globalización}

Para Anthony Giddens (2000) la Globalización es política, tecnológica y cultural, además de económica. Se ha visto influida, sobre todo, por cambios en los sistemas de comunicación, que se originan a finales de los años sesenta. Aparece una división, un nuevo muro entre dos 
grupos de Estados, un grupo de Estados - núcleo integrado- que busca ajustarse internamente al conjunto de reglas globales emergentes; y otro grupo -espacio no integrado--, que rechaza estas reglas y se mantiene ampliamente desconectado de la Globalización por su rigidez político/ cultural (Oriente Medio), por su pobreza o por su fragilidad (Asia Central, África, América Central...) (Barnett y Gaffney, 2003).

La Globalización está transformando profundamente los cimientos mismos del sistema internacional. La tipología de las amenazas y los riesgos en el siglo XXI requieren una redefinición de los términos de la seguridad nacional e internacional, donde la complejidad y la incertidumbre emergen como las principales características del nuevo entorno. El número de conflictos entre Estados está disminuyendo, el mundo no tiene por qué ser más peligroso, pero es más impredecible, más inestable. Ningún sistema de análisis permite comprender íntegramente la dinámica económica, estratégica, política y cultural de la Globalización.

\subsubsection{Nuevos riesgos y amenazas}

Tradicionalmente, las relaciones pacíficas se producían dentro de los límites del Estado, mientras la violencia se orientaba hacia el exterior. En la actualidad los límites entre la seguridad nacional y la internacional son dificiles de definir, apareciendo el concepto de amenaza "interméstica”, internacional y doméstica al mismo tiempo, que se caracteriza por "la ausencia de amenazas en la frontera y la ausencia de fronteras para la amenaza", este planteamiento añade aún más dificultades a la conceptualización de seguridad (Howard, 1987).

Hoy, la mayoría de los observadores apuntarían a una creciente incertidumbre y una creciente gama de amenazas potenciales de diversos tipos "un cuadro más complejo en comparación no solo con la era de la Guerra Fría, sino también con la última década de enfoque centrado en el extremismo violento en el Medio Oriente" (Dale, 2014, p. 7).

La paradoja es que las «nuevas amenazas», como la inseguridad ciudadana, el terrorismo, la ciber-inseguridad, la proliferación nuclear, el tráfico de drogas, la piratería marítima, la inmigración ilegal, la contaminación ambiental y el cambio climático, la pérdida de identidad na- 
cional, que amenazan a la paz y la estabilidad del mundo actual, existen desde hace mucho tiempo, y es tan solo cuando son «potenciadas» por la globalización cuando se convierten en amenazas (Kourliandsky, 2010). Como afirmaba el presidente Barak Obama en West Point:

El mundo está cambiando a velocidad acelerada. Esto representa oportunidades, pero también nuevos peligros. [...] Y mientras que los países en desarrollo adoptan la democracia y las economías de mercado, las noticias de 24 horas y las redes sociales hace que sea imposible ignorar la persistencia de conflictos sectarios y de Estados fallidos y de levantamientos populares que hubieran recibido escasa atención en la anterior generación (2014).

Hoy asistimos a una proliferación de «problemas perversos», y de consecuencias imprevistas, que parecen indicar un cierto decaimiento del liderazgo global de EE.UU. Además de no poder imponer hegemónicamente sus deseos, EE.UU. está perdiendo su capacidad de influir: EE.UU. ha perdido gran parte de su hard power con su estrategia de pivote hacia el Pacífico, y se queda sin su soft power por la aplicación de dobles estándares.

Cada problema requiere soluciones diferentes de los otros, y una solución para un problema no es válida indefinidamente. La lección que estamos aprendiendo de los conflictos como los de Irak, Libia, Siria o Mali, es que un éxito inmediato no significa en absoluto el final de los problemas estratégicos «perversos», que representan retos cambiantes y evolutivos. Desde el final de la guerra fría, ya no disponemos de un conjunto de métricas, indicadores o, técnicas operacionales que puedan ser aplicadas a todos los problemas estratégicos o que permanezcan válidos para un problema individual determinado durante todo su ciclo de vida (Watts, 2012, p. 53).

Mariano Rajoy, por entonces presidente del Gobierno español afirmaba en una conferencia ante el Curso de Estado Mayor: "La medida del tiempo ha evolucionado. Lo que hoy sucede en el otro lado del mundo se conoce a los pocos minutos en este" y al referirse a los nuevos actores: 
Estos nuevos actores se conforman de tal forma que, con muy poco poder formal, superan las barreras de todo orden: geográficas, institucionales, sociales... Ello les sitúa fuera de los límites del 'derecho internacional' que tradicionalmente se imponen los Estados, con lo que adquieren la ventaja de un adversario desconocido, difuso, ilocalizable e impredecible.

No existe una definición única de amenazas y riesgos por lo que es conveniente delimitar su significado en el ámbito de este artículo. Entendemos amenaza como toda circunstancia o agente que ponga en peligro la seguridad o estabilidad. El riesgo es la contingencia o probabilidad de que una amenaza se materialice produciendo un daño. Amenazas y riesgos en un mundo global se ven afectadas por potenciadores, que actúan como catalizadores que aumentan o reducen el riesgo de daño asociado a una amenaza. La mayoría de estos potenciadores, están asociados al fenómeno de la globalización.

Los expertos del Grupo de Alto Nivel sobre las amenazas, los desafios y el cambio, creado por el secretario general Kofi Annan en septiembre del 2003, coincidieron en que vivimos en un mundo con amenazas nuevas e incipientes que no podían haberse previsto cuando se fundó la ONU en 1945 y en que cada Estado necesita la cooperación internacional para su seguridad. Las amenazas que identificó el Informe del citado Grupo son también significativas con respecto al actual entorno de seguridad global. El informe especificó seis amenazas sin fronteras (Castro, 2011):

- las amenazas económicas y sociales, incluyendo la pobreza,

- las enfermedades infecciosas y la degradación ambiental,

- los conflictos entre Estados; los conflictos internos, incluyendo la guerra civil, el genocidio y otras atrocidades a gran escala,

- las armas nucleares, radiológicas, químicas y biológicas,

- el terrorismo, $\mathrm{y}$

- la delincuencia transnacional organizada. 
El marco de este estudio sería incompleto si no tuviéramos en cuenta que las amenazas y riesgos aparecen en un mundo global y se ven potenciadas por la propia globalización. Esta puede transformar tanto a la naturaleza de las amenazas y riesgos que afrontamos como a su propagación. Hay unos catalizadores que podrían aumentar nuestra vulnerabilidad, y a los que llamaremos "potenciadores"; el conocimiento y control de estos potenciadores nos permitirá afrontar las amenazas y riesgos - muchos de ellos compartidos-desde diversas aproximaciones.

Entre los potenciadores de riesgo se incluyen fenómenos que aumentan la probabilidad de ocurrencia de una amenaza, aumentan por tanto su riesgo. Podemos incluir entre ellos desde factores como los desequilibrios demográficos, la urbanización descontrolada, el cambio climático, la pobreza y la desigualdad, especialmente cuando esta se mantiene durante varias generaciones y la presencia de Estados frágiles o fallidos, hasta factores económicos derivados de los desequilibrios producidos por la propia globalización, o factores religioso-culturales como los extremismos religiosos o la intolerancia inter étnica.

Los dominios globalmente conectados están siendo desafiados de forma creciente por actores estatales y no estatales. Los actores no estatales, como son grupos terroristas, traficantes diversos o delincuencia trasnacional organizada, tienen interés en explotar estos dominios, también ciertos Estados desarrollan actividades para reducir la libertad de movimiento internacional. La ciberamenaza se extiende y acrecienta por una falta de normas y regulaciones internacionales, por la dificultad a la hora de atribuir ataques, por unas barreras de acceso débiles y por una facilidad relativa para desarrollar potentes capacidades de ataque.

\subsubsection{El ciberespacio}

El ciberespacio es un entorno sin fronteras, anónimo, asimétrico, que se puede emplear sin necesidad de desplazarse, lo que supone unas características muy específicas en relación con la seguridad. La Estrategia Nacional de Seguridad de Estados Unidos afirma que:

las amenazas a la ciberseguridad representan uno de los retos más graves relacionados con la seguridad nacional, la seguridad pública 
y la economía a los que se enfrenta la nación y propone reforzar la cooperación tanto entre el sector privado y el gobierno, como a nivel internacional (Rosamond, 2011).

La seguridad en el ciberespacio requiere crear una legislación específica y reforzar la resiliencia de los sistemas de gestión y comunicación y la de las infraestructuras y servicios críticos. El mayor riesgo relacionado con infraestructuras críticas se corre en lo que podríamos definir como el núcleo desarrollado e integrado del mundo, con sociedades muy industrializadas, que emplean tecnologías complejas que a su vez dependen de estructuras organizativas muy sofisticadas. Se produce la paradoja de la vulnerabilidad: cuanto más disminuye la susceptibilidad de fallos en la provisión de servicios, más grave será el impacto producido por un incidente perturbador verdadero. Se hace necesaria una "cultura del riesgo", basada en una comunicación fluida entre Estados, compañías y ciudadanos, sobre: la sensibilidad asociada a determinadas informaciones; prevención y gestión de incidentes; y una mayor flexibilidad, resistencia y capacidad de recuperación de individuos e instituciones ante la interrupción o el compromiso de los servicios relacionados con infraestructuras críticas (National Strategy for Critical Infraestructure Protection, 2009).

\subsubsection{La geopolítica del petróleo}

Los cambios estructurales en el suministro de petróleo, con un papel creciente de Rusia y los países del Golfo, favorecen el paradigma neoliberal basado en la importancia de las reglas de competición de mercado a otro neorealista, basado en la competición geopolítica. A los "pivotes geopolíticos" energéticos de producción y transporte tanto del gas -la energía del presente- ${ }^{-}$como del petróleo y en un futuro no muy lejano los corredores verdes de electricidad -la energía del futuro- entre el norte de África y Europa (Escribano, 2010).

Los movimientos populares en Oriente Medio y Norte de África, y la guerra en Libia han producido la suspensión de suministros, que, en el caso de Libia $12^{\circ}$ mayor exportador mundial, es difícil de sustituir, por las especiales características del petróleo libio (muy dulce). España se ve especialmente afectada por este problema. La sucesión en Arabia 
Saudita y las protestas contra las monarquías del Golfo, el descontento civil en Nigeria o en Irak son elementos adicionales de inestabilidad. En cualquier caso, a corto plazo, no se espera escasez de suministro (de acuerdo con un informe de The Economist ${ }^{3}$ ).

El desarrollo de tecnologías para la obtención de hidrocarburos a partir de los gases de esquisto, por medio de la fractura hidráulica o "fracking" ha supuesto un cambio importante en el panorama geopolítico. La independencia energética obtenida por EE.UU. ha liberado recursos y reducido la demanda, a lo que se suma la reducción de la demanda por parte de los países emergentes que han visto frenado su crecimiento. La reducción drástica de precios de los hidrocarburos clásicos, afecta a algunos países "rentistas" como Venezuela, o los países del Golfo Pérsico, pero también a gigantes como Rusia. Podemos hablar del retorno de la geopolítica de los hidrocarburos.

No solo los recursos energéticos darán lugar a competición geopolítica entre potencias emergentes, así los depósitos masivos de litio, descubiertos en Afganistán seguirán el mismo camino que los de Asia Central, que la madera de Siberia, el hierro de Mongolia, el petróleo de Kazajstán, el gas natural de Turkmenistán o el cobre de Afganistán, que se canalizan directamente hacia China para mantener el rápido crecimiento de la mayor población mundial (Barnett, 2010).

\subsubsection{Estabilidad financiera global}

Como consecuencia de la Globalización el capitalismo de mercado se ha extendido a gran parte del mundo, especialmente hacia Asia del Este; China, que recientemente ha entrado en la Organización Mundial del Comercio, podría ser el mayor mercado automovilístico del mundo hacia el 2020, aumentando sus necesidades de petróleo un 40\%. Este hecho puede tener efectos significativos en el ya globalizado mercado de la energía; la estabilidad política y económica es esencial para reducir el riesgo en el mercado energético (Barnett, 2002).

3. Consultar el artículo en: http://www.economist.com/node/1870957 
Para Fareed Zakaria, (una manera de concebir a China e India es como dos grandes máquinas de deflación globales que bombean bienes (China) y servicios (India) por una fracción de lo que costaría producirlos en Occidente - mano de obra cuasi esclava-. La consecuencia, combinada con el no suficiente desarrollo del mercado interno, es que ingentes cantidades de dinero no han circulado en el mercado, sino que han ido a parar a las reservas de estos países. Pero ¿qué ocurriría si la demanda de EE.UU. y Europa de productos chinos y servicios indios se reduce drásticamente como consecuencia de la crisis económica sostenida? Probablemente se reduciría la producción de ambos países y, por ende, su crecimiento económico, esto podría llevar a una reducción de la demanda energética, que a su vez produciría una disminución de los precios de mercado, sobre todo si el petróleo libio retorna al mercado.

Que ocurrirá con el gas si EE.UU. incrementa su producción de gas no natural, ¿podría una caída de los precios de los combustibles fósiles provocar otra recesión económica, liderada en este caso por China? De acuerdo con un informe del Fondo Monetario Internacional, en 2011, y por primera vez desde la crisis de 2008, el riesgo de estabilidad financiera global ha aumentado, invirtiendo la tendencia de los tres últimos años. La inestabilidad de las deudas soberanas europeas se ha extendido al sistema bancario, aumentando los créditos y los riesgos del mercado (Fondo Monetario Internacional, 2011 ). Lo cierto es que las previsiones se han cumplido y hoy los precios han caido, dando lugar a situaciones negativas en paises con una gran dependencia de exportación de materiras primas.

La seguridad económica y financiera es parte integral y requisito esencial del poder duro y, por tanto, de la seguridad. Las amenazas y riesgos en este ámbito pueden tener su origen en factores muy diversos como la actuación especuladora, la interdependencia económica o la competencia por los recursos. La lucha contra esta amenaza, aunque afecte de forma desigual a cada uno de los países miembros, es una competencia también de la UE (soberanía compartida). La crisis de la deuda soberana europea, puede afectar a la estabilidad global.

Los BRIC están especialmente preocupados por la amenaza de la carga cada vez mayor sobre la viabilidad de la zona del euro, porque si 
el euro desapareciera, el dólar volvería a ser de facto la única autentica moneda internacional, y eso significaría volver -al menos en los aspectos monetarios- a un mundo unipolar, según el experto Jean-Joseph Boillot. Es por eso, que los BRICKS hicieron un llamamiento a los países del G-20 para que actuara con rapidez y determinación a la hora de resolver la crisis de la deuda en la zona euro, de la misma manera que luchó contra la crisis financiera en 2008. Para estos países intervenir directamente en el mercado, enfrentándose a los países europeos, llevaría situaciones mutuamente incomodas - sin aumentar con ello su seguridad-, ya que los BRICKS necesitan a su vez de fondos para resolver sus propios problemas socioeconómicos internos, como inflación, un crecimiento más lento, o la creación de burbujas inmobiliarias.

\subsubsection{Problemas medioambientales}

A los problemas producidos por el hombre - como los que sufre China-, paradigma de desastres medioambientales, o en África, donde la contaminación de ríos y lagos puede amenazar su futuro. El aprovechamiento excesivo de acuíferos y el nacionalismo a la hora de disponer de agua sin respetar los acuerdos internacionales, en un mundo dominado por los ríos y acuíferos transnacionales suponen un grave riesgo de conflicto a medio plazo. El control del curso, por parte de los países ribereños, de las cabeceras de los ríos por medio de pantanos que permiten nuevos proyectos agrícolas, o simplemente para la producción de energía eléctrica, se está convirtiendo en rutina, con el riesgo que supone para el suministro de los países de la cuenca baja.

En casos como el del casi desaparecido Mar de Aral, se pueden añadir multitud de otros casos en el sudeste asiático, cuenca del Nilo, Tigris y Éufrates, Jordán, entre otros, hasta el punto de preguntarnos si el agua no será el petróleo -el oro azul- del siglo XXI y estará sujeto a los avatares del mercado. El constante aumento de la urbanización con una mayor demanda de agua per cápita y la desaparición de tierra agrícola son situaciones irreversibles. 


\subsubsection{1 ¿Se está produciendo un cambio político?}

No es el objetivo de estas letras opinar sobre lo que los expertos aún discuten, pero las noticias recientes de inundaciones en el sudeste asiático, o huracanes y tormentas tropicales en México y Centroamérica, parecen decir algo. Los fenómenos no son nuevos, pero sí lo es su frecuencia y en algunos casos su intensidad.

A las temperaturas inusualmente altas en Rusia y Canadá con sus efectos positivos - tierras adicionales para el cultivo- ${ }^{-}$y negativos -incendios salvajes como el que asolaron a Rusia (el verano más caluroso en 130 años)-, hay que sumar un invierno extremo en zonas de EE.UU. o China, un incremento notable del número de inundaciones a lo largo del mundo desde Australia a Zimbabwe, pasando por Sudamérica, África Occidental o China. A ello se suman las tormentas, y tornados o la pertinaz sequía que ha sufrido el África del Este y que ha dado lugar a una gran hambruna en Somalia y alrededores.

\subsubsection{El Ártico}

Desde el final de las hostilidades que dominaron la Guerra Fría, el Ártico se ha caracterizado, en apariencia, por su desmilitarización e institucionalización global. Pero la realidad es más compleja y se producen simultáneamente fenómenos contrapuestos marginalidad-centralidad, aseguramiento-des aseguramiento, militarización-desmilitarización (Rosamond, 2011). A pesar de la institucionalización creciente del Ártico, se mantiene las tensiones geopolíticas por la competición por los recursos naturales y reclamaciones de soberanía.

La conexión entre cambio climático y la extensión de la soberanía es el núcleo de los debates de seguridad en esta zona, guiada más por la "realpolitik" que por la gobernanza global. El Ártico es, posiblemente el área más afectada por el cambio climático y este a su vez implica una competición para obtener nuevos territorios y recursos entre las cinco potencias árticas. Las extensas terrazas continentales podrían ser la mayor superficie no explorada con prospecciones petrolíferas que queda en la tierra. A lo que hay que sumar las nuevas rutas para el comercio internacional hasta ahora inaccesibles (Asia-Occidente vía Rusia). La producción agrícola podría mejorar con estaciones más largas y cálidas. 


\subsubsection{El nuevo gobierno mundial}

Además de los ya citados BRIKS, aparecen multitud de grupos informales a los G (G2, G77, G20,...) se unen VISTA (Vietnam, Indonesia, Sudáfrica, Turquía y Argentina); CIVETS (Colombia, Indonesia, Vietnam, Egipto, Turquía y Sudáfrica); MIKT (Indonesia, Turquía, México y Corea), o el Next 11. Para Álvaro de Vasconcelos el G-20 es el primer reconocimiento por parte de los principales poderes, de que el gobierno mundial necesita adaptarse al nuevo panorama de distribución de poderes. Tanto los EE.UU. como la UE tienen que aceptar la dura realidad a pesar de su fuerza combinada, de que Occidente no tiene capacidad para afrontar retos importantes, particularmente cuando tiene que resolver su crisis financiera.

La idea del G-20 está ligada al fracaso del sistema e instituciones Bretton Wood (Conferencia Monetaria y Financiera de las Naciones Unidas, realizada en el complejo hotelero de Bretton Woods, en 1944), con el reconocimiento de la necesidad de encontrar soluciones globales a problemas que adquieren dimensión global. Es una señal del fin del dominio occidental y de la emergencia de un orden multipolar tanto en pollita como en economía.

\subsection{Una visión próxima}

Tras haber visitado el mundo global como sistema, aproximamos la imagen a nuestro punto de vista - mediterráneo y eurocéntrico- para observar nuestro entorno más próximo: la Unión Europea, Europa en su conjunto; el mundo árabe, la región MENA. Zonas otrora muy tranquilas, donde acontecimientos como la fuerte crisis económica - particularmente la crisis de las deudas soberanas que vive gran parte de la UE-, y las denominadas Primavera Árabe, que tras su estrepitoso fracaso podría haber dado lugar y en sitios como en Libia han dado lugar a lo que algunos "laicos" árabes califican como el "infierno islamista", que centraron la atención mundial distrayéndola de hambrunas, conflictos enquistados y desastres naturales. 


\subsubsection{El Mediterráneo}

Si tras leer la prensa tuviéramos que definir dónde está el centro de gravedad de los problemas mundiales sin duda el Mediterráneo Norte y Sur se llevarían el primer puesto. Se han gastado ríos de tinta para describir la crisis de la deuda europea, particularmente en los países del sur - muy especialmente Grecia- por un lado; y a la llamada por prensa occidental la Primavera Árabe, que como su propio nombre indica se inició en invierno en todos los países árabes. Pero los brotes verdes se han helado dando lugar a lo que los periódicos liberales árabes pronostican como un otoño (algunos lo llaman infierno) islamista, o un retorno al rancio nacionalismo árabe.

$\mathrm{Al}$ conflicto de Libia le han seguido las guerras de Siria e Irak, y la emergencia del Estado Islámico (DESH). En su conjunto representan el fracaso de la aplicación del "poder blando": No solo no es liderado con el ejemplo, sino que la situación actual, en todos sus aspectos, es peor que la anterior a las revueltas de 2011.

\subsubsection{La "smart defence" de la OTAN o la "pooling \& sharing" de la UE}

El 19 de noviembre de 2010, durante la Cumbre de Lisboa, la OTAN aprobó el nuevo concepto estratégico, un documento de 11 páginas titulado Empeño Activo-Defensa Moderna. Había gran expectación sobre este documento, largo tiempo esperado porque podría producir lo que el embajador de EE.UU., Ivo Daalder, llamaba la "OTAN versión 3.0" y que convertiría lo que ya era una alianza global en un actor global. La OTAN pasaría a ser una organización experta en "practice of talking" a otra en "practice of doing", con las tres C: Defensa Colectiva (de acuerdo con el artículo V del Tratado de Washington) y Gestión de Crisis y Seguridad Cooperativa.

El nuevo concepto estratégico de la OTAN dice que el terrorismo "supone una amenaza directa a la seguridad y prosperidad de los ciudadanos de los países de la OTAN, y de una forma más amplia a la prosperidad y estabilidad internacional..." y que la inestabilidad o los conflictos más allá de las fronteras de la OTAN "pueden amenazar di- 
rectamente la Seguridad de la Alianza, incluyendo mediante el fomento del terrorismo y de las actividades ilegales transnacionales...".

De hecho, aunque la tarea suprema de la OTAN continua siendo la defensa del territorio de la OTAN y de la población de los aliados, el concepto estratégico elimina las limitaciones territoriales de los anteriores conceptos, y las amenazas que singulariza son transnacionales o globales. Es como le definen algunos expertos una alianza atlántica, enfocada en el globo. Reafirma el artículo 5 del citado tratado de Washington pero globaliza la idea que está detrás del mismo: la OTAN tiene que proteger, como siempre, pero ahora es contra amenazas que no reconocen fronteras convencionales, como son el terrorismo, la proliferación de armas de destrucción masiva, o las ciberamenazas. La OTAN no solo tendrá que disuadir y defenderse contra cualquier amenaza de agresión, sino también proporcionar defensa colectiva contra amenazas emergentes de seguridad que amenazan aliados individuales o la alianza en su conjunto. La defensa colectiva se aplica a toda la gama de desafíos de seguridad que se contemplan en la sección que trata sobre la evaluación del entorno de seguridad, que comienza con "The conventional threat", para continuar con los nuevos desafíos a la seguridad.

El Tratado de la UE por su parte, establece la competencia de la Unión en materia de la Política Común de Seguridad y Defensa (PCSD) y recoge el derecho de los Estados miembros de consultarse sobre cualquier cuestión que revista un interés general en este ámbito. Cualquier actor que pretenda tener una presencia global hoy debe tener un equilibrio entre las tres D (Diplomacia, ayuda al Desarrollo, Defensa). Europa tiene bien desarrollados su ayuda al Desarrollo y -tras la creación del Servicio exterior-y su Diplomacia (los poderes blandos). Pero la UE aún tiene que desarrollar su Defensa si quiere convertirse en un actor global.

El Tratado de Lisboa ha hecho progresos. La UE ha aprobado con el Tratado de Lisboa las cláusulas de asistencia mutua y de solidaridad, con lo que se aborda una política común de defensa, que podría conducir - con el tiempo- a una defensa común. ¿Quién puede afirmar que en un futuro no se incluyan nuevas amenazas que acerquen más esta cláusula a la PESC/PESD y se acabe profundizando, si cabe, en la cláusula de 
asistencia mutua y los mecanismos que desde esta se pueden poner en marcha?

Lo cierto es que las discrepancias surgidas con la denominada "crisis de los refugiados" en el segundo semestre del 2015 y primero del 2016, suponen un retroceso importante para las citadas políticas europeas. La defensa de los intereses compartidos a través de la UE es sin duda un futurible, optimista pero futurible, pero mientras tanto es la OTAN la que ha demostrado disponer de medios y garantías suficientes para defender esos intereses -individuales o compartidos- de sus aliados. Un cambio de la política exterior de los EE.UU. hacia una visión "America First" podría actuar como catalizador de este proceso.

\subsubsection{El despertar árabe}

La conocida en Europa como la Primavera Árabe -término acuñado por periodistas occidentales- podría dar lugar al escenario menos deseado, lo que algunos "laicos" árabes ya llaman el "infierno islamista". En lo que se podría calificar como una gran chapuza estratégica, ha sido el apoyo euro-atlántico a unos levantamientos de jóvenes liberales blogueros, de clase media-alta, contra un poder establecido. El resultado podría ser exactamente contrario al pretendido, un retroceso (secular) en el propio Mediterráneo, es decir, un invierno árabe. Los dos países más afectados (excluyendo a Libia que ha sufrido una intervención militar externa), han sido el pequeño Túnez y el gran Egipto, los dos países con economía más diversificada y con mayores cotas de libertad en Oriente Medio y el Norte de África, es decir, el sueño de liberalización y apertura económica del FMI y europeo.

Si a lo anterior sumamos el complejo asunto Libio, y más recientemente el sirio, auténtico rescoldo reactivado de las revueltas árabes, ha dado lugar a una situación en la que la confianza global hacia Occidente se encuentra en niveles muy bajos y cunde el convencimiento de que Occidente emplea el doble estándar a su conveniencia. El bloqueo a cualquier resolución en el Consejo de Seguridad sobre Siria, propuesta por Francia-Reino Unido y apoyada por EE.UU., con la aplicación del veto Chino y Ruso, y el no apoyo de países como India, Brasil, Sudáfrica o 
Alemania, miembros no permanentes del CS de las ONU fue más que sintomático: Se está produciendo una clara línea de división Norte-Sur que amplía el abismo cultural ya existente.

Para pensadores árabes (como AbduIlah y Hana Al Bayaty) el levantamiento tunecino no fue otra cosa que el resultado natural del fallo del modelo de globalización y el impase que afecta al tercer mundo. El modelo de globalización en el mundo árabe consiste en abandonar el carácter árabe-musulmán del Estado responsable del bienestar de los ciudadanos. El modelo impuesto por la fuerza, como en Irak, o por presión económica como en Egipto o Indonesia, o su adopción por los países productores de petróleo ha dado lugar a Estados cuya única misión parecía diseñar leyes y proteger los intereses del capitalismo propio y ajeno. Este modelo habría servido para enriquecer a los más ricos, empobrecer a la clase media, y marginalizar a los pobres (Albayaty, Al Bayaty y Douglas, 2011).

Cuando el grupo de Facebook llamado "Todos somos Khaled Said" se formó como consecuencia de su muerte, y con el apoyo de la diplomacia pública de EE.UU., casi medio millón de personas se unen a este. La reclamación inicial era modesta: que se sometiera a los culpables de su muerte a un juicio justo. El administrador del grupo, Wael Ghonim, había organizado varias protestas silenciosas y, posteriormente, una en las puertas del juzgado donde se veía el caso, pero la participación en esos casos no había superado las cien personas, por el peligro de su propia seguridad física.

Estos no han sido los primeros intentos de usar Internet para oponerse al Gobierno, desde 2004 algunos blogeros habían trabajado con el movimiento Kefaya (basta ya!) para oponerse a que Mubarak se presentara a una quinta reelección en 2005 y para exponer al dominio público los casos de tortura (Al-Berry, 2011). Cuando se fija la fecha para la "revolución” de 2011 muy pocos se lo tomaron en serio. Pero, el 25 de enero, la generación de Facebook demostró que tenía razón: se organizaron, e iniciaron una marcha pacífica al grito de "pacífica, pacífica", en un intento desesperado de evitar los disparos de la policía (Al-Berry, 2011). 
En mi artículo publicado por el Instituto Español de Estudios Estratégicos -"Cairo 3.0" - cito una serie de hitos que ayudan a entender la situación de partida. Ante todo la situación general económica ha cambiado. A pesar de la mejora de los datos macroeconómicos del país y de las reformas estructurales propiciadas por EE.UU. y la UE, estas mejoras no se han trasladado al pueblo, que se ha visto afectado, -especialmente los más desfavorecidos- por un importante incremento de los precios de los productos básicos, entre ellos el pan subvencionado. Hay que recordar que Egipto es el primer importador mundial de trigo, cuyo inmenso y creciente coste (aumento del precio del grano y de la población egipcia) tiene que ser pagado con el turismo y con los ingresos del canal de Suez. La primera consecuencia de esta "ciber-revolución" podría ser una hambruna, que afectaría a los que no participaron en la misma: a los pobres de la galabeya. La "ciber-revolución" no ha sido un levantamiento popular de los más desfavorecidos luchando por el pan, ha sido un "revuelta" burguesa luchando por las libertades.

\subsubsection{Libia, comienzo y fin del R2P. ¿Una guerra sacra o posheroica?}

La doctrina de la responsabilidad de proteger fue adoptada por la ONU en 2005, cuyo objetivo era facilitar el desarrollo de una sociedad civil potente en los países árabes. The Economist (2011) mantiene que los más escépticos consideran que puede ser fácilmente manipulada: una cobertura para el imperialismo, o incluso un incentivo para matar (porque aunque no hubiera una masacre inminente, un señor de la guerra sin escrúpulos podría tener la tentación de ingeniar una contra su propio pueblo para provocar una intervención externa) $)^{4}$.

La doctrina posiblemente morirá en Libia. En opinión de David Rie$\mathrm{ff}^{5}$, "para aquellos de nosotros que temíamos que la aplicación de la R2P supondría tan solo una justificación para la guerra, nuestros temores se han visto justificados", y opina que se han producido dos niveles de responsabilidad: "los viejos poderes imperialistas hacen las reglas...pero la

4. http://www.economist.com/node/18709571

5. Un defensor de la $\mathrm{R} 2 \mathrm{P}$ reconvertido en crítico de la misma. 
votación sobre Libia pasó porque los no occidentales, Rusia y China, no emplearon su derecho a veto en el CS".

Lo cierto es que en Libia se produjeron dos guerras a distinto nivel, una -la de Sarkozy y la OTAN- aérea, tecnológica, sin víctimas propias, realizada a distancia y sin que afecte a los países que la ejecutan; sin duda una guerra posheroica. Por otro lado está: una auténtica guerra "sacra" entre las fuerzas leales a Gadafi -abandonado por todos sus amigos occidentales (que no hace tanto, se lo "comían" a besos)- y una oposición, fuertemente apoyada por Occidente, esta guerra "sacra" continua hoy en día y no se vislumbra una solución a corto plazo. ¿Será este el futuro de lo que llaman "smart power"? Las intervenciones ante la crisis siria así parecen indicarlo, y el resultado ha sido similar a una guerra sangrienta de todos contra todos, otro desastre "libio".

\subsection{2 África del pasado colonial al continente del futuro}

La mayoría de los países africanos independientes son Estados creados colonialmente que tratan de convertirse en unas naciones más coherentes. Por el contrario, en el caso de un país como Somalia, que era una nación indígena, la lucha es por convertirse en un Estado más estable y más inclusivo. Pero debido a que nacionalidad y Estado se interrelacionan en el siglo XX, ambas categorías de países siguen sufriendo crisis gemelas de identidad y autoridad en la era poscolonial.

En gran medida, la mayor amenaza para la identidad nacional en el África independiente es el legado de fronteras artificiales creadas por las potencias coloniales. La mayor interrogante que pende sobre la estabilidad del Estado ha sido a menudo el ejército permanente, que también fue una creación colonial. Antes del colonialismo, la mayoría de las sociedades africanas creaban ejércitos únicamente cuando era necesario en tiempos de conflicto. No tenían regimientos permanentemente en armas, tanto si hubiera conflicto como si no. Lo que el colonialismo crea es una máquina militar con una tecnología importada de destrucción que se adelanta al resto de la infraestructura. Tanto la nación como el Estado africanos han estado bajo presión de las fuerzas gemelas que suponen unas fronteras artificiales y unas relaciones cívico militares inestables (Elaigwu, 1993, p. 435). 
Ambos procesos de construcción de la nación y el Estado pueden ser simultáneos, y con frecuencia se superponen. Para muchos Estados africanos, el Estado ha precedido a la nación. Muchos grupos de los pueblos se empaquetaron arbitrariamente en una unidad territorial, que luego formó una entidad geopolítica llamada Estado. Para muchos de los pueblos de estos Estados, no había ninguna identificación con el Estado como símbolo de un pueblo, una comunidad política. De hecho, la mayoría de estos grupos quedarían expuestos a los otros en el período terminal colonial, cuando los amos coloniales plegaron su paraguas político y arriaron su bandera (Elaigwu, 1993, P. 439).

Para estos pueblos no hubo intercambio de valores comunes, creencias y actitudes entre los pueblos de los nuevos Estados que creara una cultura política. Además, surgiendo principalmente después de la década de 1960, los períodos de la construcción del Estado en muchos Estados africanos han sido cortos. Como los experimentos en la construcción del Estado continúan, por lo que también continúan experimentando la construcción de la nación (Elaigwu, 1993, p. 439).

Para Sheldon Gellar (1972, pp. 40-41) los procesos de construcción de la nación y el Estado han sido testigos del desarrollo de "Estados nación" que reconocen la paradoja de la integración nacional, es decir, de "la diversidad en la unidad" y no solo "la unidad en la diversidad". El proceso de construcción de la nación podría entrañar la creación de "Estado-naciones", así como de "Nación-Estados" como productos finales.

En opinión de Joseph Ki-Zerbo, Ali A. Mazrui y Christophela WondjI, dos dialécticas conocidas han condicionado valores políticos en África en el período desde 1935: la dialéctica entre el colectivismo y el individualismo, por un lado, y la dialéctica entre el pluralismo y el nacionalismo, por el otro. Las tradiciones más antiguas del colectivismo a veces se han enfrentado con nuevas formas de individualismo; mientras que los principios del pluralismo han interactuado con los valores del nacionalismo.

Los países europeos y americanos han entrado, en su mayor parte, en un ciclo de crecimiento débil o nulo. La población ha dejado de crecer, mientras que su edad media se eleva de forma inexorable siendo Japón 
el caso extremo. Por otro lado, África, desde comienzos del siglo XXI, ha entrado en un ciclo de crecimiento del orden del 5\%. Los tigres y dragones asiáticos están en pleno crecimiento, pero ya no están solos, están siendo alcanzados por los leones económicos africanos. En 2008 el PIB de África en su conjunto es de 1600 millardos de dólares, equivalentes al de Brasil o Rusia, y se prevé que pueda aumentar en 1000 millardos para 2020 gracias la agricultura y la industria modernas (Ben-Yahmed, 2011).

Las prospectivas de población activa nos indican que para 2040 África dispondrá de la mayor población activa mundial, con más de 1100 millones, superando a India, y a China que habrá empezado su curva descendente a partir del 2015 y no hay que olvidar que de nuevo la población es el factor determinante para el PIB. Como lo fue hasta comienzos del siglo XCIII - hasta la revolución industrial-, cuando la India con sus 165 millones de habitantes y China con sus 138 disponían del 50\% del PIB mundial, mientras que Gran Bretaña con sus 10 millones tan solo suponía el 3\%. La población de África pasará de 1000 a 2000 millones para el 2050, lo que supone pasar del 12 al 20\% de la población mundial, que además será la más joven. Las perspectivas de África son inmejorables, pero para ello, es necesario un buen gobierno (Ibrahim, 2011). Los intercambios comerciales Sur-Sur de África subsahariana (con Asia, intraafricanos, Oriente Medio, América Latina) suponen hoy en día un 50\% del total, cuando en 1990 representaban menos del 30\%. El crecimiento de África entre 1970 y 2008 es el tercero solo detrás de Asia y Oriente Medio, pero además es el más rápido en la última década.

\subsubsection{1 África subsahariana ¿Un vacío sistémico?}

África es algo más que un vacío sistémico, África es el futuro. Si la población será en el futuro el factor esencial para definir el potencial PIB, África será una potencia que igualará y superará a China e India. África es hoy en día escenario o tablero -junto con Iberoamérica- donde las potencias juegan las partidas simultáneas por los recursos. China, EE.UU., India, la UE, Brasil, Japón, Corea, Irán, Arabia Saudita y otros tratan de colocarse en posición de ventaja de cara al futuro. La población más joven se encontrará en África, mientras que China sufrirá un 
envejecimiento sustancial. La competición entre potencias por recursos estratégicos y escasos que puede dar lugar a un nuevo panorama geopolítico con nuevos pivotes entre países productores y la potenciación de los corredores energéticos.

La casi completa ausencia de guerras interestatales ha dado lugar a una "paz negativa" en África, donde la violencia estructural, potenciada por la fragilidad de determinados Estados extremadamente débiles y la delincuencia trasnacional, da lugar a la elevación de ciertos riesgos a la categoría de casi amenazas. A conflictos interminables como el de los grandes lagos o de Somalia, se unen nuevas líneas de fractura, como el arco de inestabilidad que recorren el Sahel de lado a lado. Las soluciones buscadas aquí son más "inteligentes". La extensión del terrorismo ligado a DAESH está actuado como potenciador de esta inestabilidad que ya parece crónica.

No obstante, las soluciones regionales con el apoyo de la UE o de los EE.UU. podrían ser la clave para la solución de varios de estos conflictos, si la "maldición de los recursos" lo permite.

\subsubsection{Delincuencia trasnacional organizada}

La delincuencia trasnacional organizada se ha convertido en una de las principales amenazas a la seguridad que se ve potenciada por su aparición en una zona de Estados extremadamente frágiles o fallidos en el Sahel y en África Occidental, Central y Oriental. La ruta de los diversos tráficos asociados con la citada delincuencia trasnacional (que mueve cantidades ingentes de dinero negro) pasa en algunos casos por España. Su creciente interrelación con el terrorismo, con los grupos violentos y con la delincuencia local hace que los riesgos se potencien entre sí. Para responder a esta amenaza de carácter global es esencial una aproximación integral y compartida.

\subsubsection{Sudán ante su segunda división}

En el ámbito regional, un hecho singular ocurrido en este periodo cercano a la llamada "Primavera Arabe", fue el referéndum para la independencia del Sur de Sudán, cuyos resultados superaron el 98\% de 
votos favorables a la independencia. La publicación de los resultados hubiera supuesto en condiciones normales un auténtico shock en el mundo árabe, ya que implicaba la pérdida por parte de Sudán -y del mundo árabe- de una extensión aproximadamente igual a la de España. Estos resultados se anunciaron durante los momentos más intensos de la crisis egipcia.

Pensar, como sugerían ciertos rumores en una "teoría de la conspiración” y que EE.UU. podría estar detrás de los incidentes junto a Israel es, como poco, surrealista. Mientras que es descartable que EE.UU. estuviera en el origen, no es inverosímil que actuara posteriormente para alcanzar un acuerdo entre las partes que evitase una escalada explosiva. Los Estados Unidos han tenido ocasión de poner en práctica -con éxito- lo que su nueva Política Nacional de Seguridad califica de Smart Power-combinación del Soft Power (DD diplomacia y desarrollo) con la sabia aplicación puntual del Hard Power (D defensa)-.

La desconfianza hacia EE.UU. y Europa, justificada o no, se ha extendido por el África subsahariana, tras la desaparición de Sudan, el mayor país de África, y las intervenciones "humanitarias" francesas en el África francófona. Hay recelos sobre si EE.UU. no estaría poniendo en práctica su "destino manifiesto" a nivel global y tras fragmentar Yugoslavia, de acuerdo con el diseño Bush, continuaría con otros países, particularmente en el Gran Oriente Medio, para dividirlos en unidades étnicamente compactos, que permitan justificar la existencia de Israel. La segunda división de Sudán parece haber comenzado,... ¿ ¿será Egipto - península del Sinaí- el siguiente en la lista?

\subsubsection{Somalia, terrorismo, piratería, hambre}

Las amenazas asociadas a los Global Commons están emergiendo en los últimos tiempos; entre ellas destaca la piratería marítima, que se desarrolla en varias zonas del mundo y que, en la zona del estrecho de Ormuz y el Mar Rojo, ha provocado el despliegue de operaciones tanto de la OTAN como de la UE con participación de las Fuerzas Armadas españolas. Es una amenaza que en el caso español ya se ha materializado en varias ocasiones, por lo que el riesgo de repetición es alto. 
Somalia es la muestra fehaciente de la debilidad de las grandes potencias, incapaces de controlar un país prácticamente fallido, se centran en arreglar otros que aún funcionan. Terrorismo, conflictos, piratería o hambruna son términos asociados a Somalia. Pero Somalia y sus hambrunas solo aparecen en las noticias de forma accidental y, si no apareces en las noticias, simplemente no existes. Sería interesante ver a Ban Kimoon más preocupado por Somalia.

\subsubsection{El sahel AQMI (Al-Qaeda Magreb Islámico)y recursos naturales}

El Sahel, una zona amplia de territorio que ocupa nueve millones de kilómetros cuadrados y abarca nueve países, siempre ha constituido un área de tránsito con un constante flujo de personas, comercio, finanzas y grupos religiosos. Durante los últimos veinte años el crimen organizado ha tenido una gran oportunidad de desarrollo en ese lugar, ya sea mediante la utilización de redes tradicionales o apropiándose de zonas donde no existe control estatal. Esta región también se encuentra afectada por crisis interminables y Estados debilitados, a pesar de su innegable importancia estratégica proveniente de recursos naturales: petróleo, oro, fosfatos, diamantes, cobre, hierro, carbón, níquel, zinc, bauxita, uranio, plutonio, magnesio, cobalto, plata, cromo y maderas de calidad.

Pese a la abundancia de recursos naturales, la fragilidad de la mayor parte de los Estados del Sahel y la inestabilidad regional hacen que perpetúen condiciones que generan inseguridad. El rápido crecimiento demográfico (excepto en el Magreb, que se encuentra en una transición demográfica), corrupción, pobreza endémica, analfabetismo, y conflictos incesantes generan asentamientos desplazados y migración ilegal. El resultado, frecuentemente, se traduce en personas forzadas a formar parte de grupos criminales o rebeldes, a cambio de beneficios del tráfico o protección.

\subsubsection{Tráfico de armas ligeras y saqueo de recursos}

Las noticias recientes sobre la desaparición de Libia de grandes arsenales de armas ligeras, e incluso de misiles portátiles tierra aire, y su 
posible transporte a los países vecinos, Egipto, Argelia y los países del Sahel, han vuelto a poner de moda un viejo problema. El Programa de las Naciones Unidas para el Desarrollo (UNDP) afirma que más de 100 millones de armas ligeras se encuentran actualmente en circulación en todo el territorio africano. En el caso de África Occidental la cifra se sitúa en torno a los 8 millones, incluyendo 100.000 Kalashnikov solo en el Sahel.

Los conflictos regionales y rebeliones internas juegan un papel decisivo en el tráfico de armas, que han potenciado conflictos en Costa de Marfil, Guinea-Bissau, Liberia y Sierra Leona, las revueltas Tuareg en Malí y Níger, así como la rebelión Salamanca. El declive político y la ruptura del Frente Polisario, al igual que la proximidad del Sahara Occidental a Mauritania, han creado un espacio "sin gobierno" que han explotado los miembros de esta organización para ganar dinero mediante el contrabando de armas. Los campos de refugiados del Frente Polisario Saharaui situados en el suroeste argelino, sur de Libia, y norte de Mali también constituyen zonas de tránsito. Gracias a la localización estratégica en la que se encuentra, la ciudad de Tinduf se convierte en el puente ideal entre el Sahel occidental y el Sahel oriental.

La parte más positiva en el Sahel la pone Níger, país que con sus 15,5 millones de habitantes gozara en 2012 del segundo mayor índice de crecimiento africano 12,5\% frente, en comparación, al 5,5 de 2011. Se situará justo detrás de Sierra Leona, con un crecimiento esperado del 51,4\% y delante de Angola con un crecimiento del 10,8\%. Las exportaciones petrolíferas de Níger se deberán triplicar y en lo relativo al uranio, principal recurso del país, pasando a ser del sexto al segundo lugar mundial.

Se ha producido un aumento de la actividad terrorista de AQMI desde abril de 2011 en los atentados, incluyendo varios atentados suicidas, principalmente dirigidos contra las fuerzas de seguridad argelinas. Algunos analistas de inteligencia han señalado que este crecimiento del número de ataques terroristas atribuidos a AQMI, puede amenazar la estabilidad política de Argelia, estaría relacionado con la caída del régimen gadafista en Libia, debido al aumento en la disponibilidad de armas y explosivos (Laborie, 2011). 


\subsection{América Latina}

Un continente en el que las instituciones se inventan cada lustro, se descuartizan cada década y no funcionan bien la mayor parte del tiempo, difícilmente puede alcanzar sus metas. El hilo de Ariadna es en esta historia el mayor dolor de todos, lo tejido en el día se desteje en la noche y lo que se vuelve a tejer tiene un punto diferente (Mesa, 2010).

De acuerdo con Merke (201 1, p. 23), se puede caracterizar a América Latina por ciertos hechos que se acentúan en Sudamérica:

1. En doscientos años ningún Estado ha desaparecido y solo uno ha nacido.

2. El principio de Uti Possidetis (como poseías, continuarás poseyendo) se acordó incluso antes de la independencia de Portugal y España, permitiendo delimitar las fronteras estatales de forma mucho más pacífica que en Europa.

3. América Latina es la región del mundo que dispone de la mayoría de los acuerdos bilaterales y multilaterales relacionados con la solución pacífica de los conflictos, así como el «récord mundial de la adjudicación y el arbitraje».

4. América Latina es una zona libre de armas nucleares.

En resumen, la supervivencia del Estado ha estado prácticamente garantizada, las guerras han sido escasas, y la legalización de los conflictos ha sido la norma. Esto no quiere decir que la violencia política ha sido erradicada, sino más bien «ha habido una concepción limitada de la fuerza dentro de una fuerte cultura diplomática» o ha sido confinada dentro - en contraposición a través- de las fronteras. Por lo tanto, la seguridad ha adquirido una connotación interna más que internacional. Brasil es un producto de este entorno histórico y geográfico, y como tal, lleva más parecidos a sus vecinos que a cualquiera de los estados europeos tradicionales o las nuevas potencias emergentes. 


\subsection{1 ¿El patio trasero de EE.UU.?}

Durante el mandato del presidente Obama se han producido cambios notables en la aproximación de los EE.UU. hacia América Latina: El reconocimiento de Cuba, el final de la doctrina Monroe y la presencia China son elementos de interés.

\subsubsection{El reconocimiento de Cuba}

La lógica de la Guerra Fría impregnó las percepciones latinoamericanas sobre seguridad y defensa y definió de forma muy precisa las «misiones» de las fuerzas armadas de la región. La «Doctrina de la Seguridad Nacional» se superpuso al concepto decimonónico de seguridad basada en la soberanía nacional, la integridad territorial y el mantenimiento del orden interno, por lo que los cambios sociales y políticos fueron considerados intentos de infiltración y subversión comunista.

Si la defensa contra el «enemigo exterior» fue asumida por EE.UU., la lucha contra el «enemigo interior» fue una de las funciones primordiales de las Fuerzas Armadas nacionales en la totalidad de América Latina. La guerra antisubversiva fue el resultado inmediato de Doctrina de la Seguridad Nacional, y la lucha contra el comunismo, sirvió para justificar la ruptura del ordenamiento democrático y la dictadura militar.

Existen algunas constantes de la política norteamericana hacia la región que han permanecido intactas a pesar del fin de la Guerra Fría. Para Blanco (1998), la más significativa ha sido la permanencia de una perspectiva de «Guerra Fría» con respecto a Cuba. Este comportamiento no se podía explicar por el potencial de amenaza que pudiera representar Cuba tras la desaparición de la Unión Soviética, sino por razones de índole interna en la política estadounidense, relacionadas con la cuestión migratoria y el lobby que mantienen en el Congreso los cubanos anticastristas residentes en los Estados Unidos.

Si 2015 fue un año decisivo en las relaciones entre Estados Unidos y Cuba con la reanudación de las relaciones diplomáticas y la apertura de embajadas, se espera que 2016 sea un año en el que hay que hacer frente a los difíciles problemas aún pendientes. Entre esos problemas están la migración, con miles de cubanos intentando llegar a los Estados Unidos, 
y el futuro económico de Cuba, ahora que su acuerdo preferencial sobre petrolero con Venezuela parece estar tras la victoria de la oposición en las elecciones al Congreso que este último país ganó. Para los cubanos, lo más importante es conseguir el levantamiento del embargo, una propuesta difícil en un año complejo para EE.UU.

La administración Obama llega a su fin, y los cubanos saben que su ventana de oportunidad es limitada, y que tras el final del mandato de Obama, las cosas podrían cambiar drásticamente.

\subsubsection{El fin de la era de la Doctrina Monroe}

En los primeros días de nuestra República, Estados Unidos tomó una decisión acerca de su relación con América Latina. El presidente James Monroe, que era también un ex secretario de Estado, declaró que Estados Unidos unilateralmente, y como hecho consumado, actuaría como protector de la región. La doctrina que lleva su nombre hacía valer su autoridad para intervenir y oponerse a la influencia de las potencias europeas en América Latina. Y a lo largo de la historia de nuestra nación [EE.UU.], los sucesivos presidentes han reforzado esta doctrina y tomado una decisión similar (Kerry, 2013).

La Doctrina Monroe sirvió de herramienta legitimadora durante el primer siglo de intervención de Estados Unidos en el exterior. Hasta la Primera Guerra Mundial, los intereses de política exterior de Estados Unidos se encontraban mayoritariamente en América Latina. La citada doctrina prevenía a los Estados europeos de intervenir en el continente americano. De ella se deriva la doctrina del "destino manifiesto", que se desarrolla a través de dos estrategias básicas:

- La exportación del modelo norteamericano.

- La exclusividad de acción de los Estados Unidos en el continente.

Tanto el almirante Mahan, como el presidente Roosevelt, basaron sus ideas en la doctrina Monroe. Mahan (1890) en su libro The influence of sea power upon history, une por primera vez el concepto de «interés nacional» con Iberoamérica: 
«El interés nacional de los Estados Unidos en el mundo, por encima de ideologías, será asentar y exportar su modelo político, fruto de nuestros principios de libertad, por nuestro continente natural, especialmente en los territorios más cercanos, preservándole a este de injerencias nocivas y caducas...».

Con la política del Gran Garrote, Roosevelt presionaría a los países iberoamericanos, particularmente a los caribeños, con una intervención armada amparada en el «derecho» de los EE.UU. a intervenir en asuntos de otros países en defensa de los intereses de ciudadanos estadounidenses, de acuerdo con su propio corolario de la doctrina Monroe.

El cambio más dramático, en sentido contrario, se ha producido en un momento en que Oriente Medio, Afganistán y China parecían monopolizar la política exterior norteamericana. En palabras del secretario de Estado John Kerry (2013):

Hoy, sin embargo, hemos hecho una elección diferente. La era de la Doctrina Monroe ha terminado. La relación que buscamos y que hemos trabajado mucho para fomentar no se trata de una declaración de los Estados Unidos acerca de cómo y cuándo va a intervenir en los asuntos de otros estados americanos. Se trata de todos nuestros países viéndose entre sí como iguales, compartiendo responsabilidades, la cooperación en cuestiones de seguridad, y no adherirse a la doctrina, sino a las decisiones que tomamos como socios para promover los valores y los intereses que compartimos.

\subsubsection{Papel futuro de los EE.UU. en América del Sur}

José Luis Fiori (2009) no considera probable que Estados Unidos renuncie a lo que tradicionalmente ha considerado sus tres justificaciones para intervenir y que han orientado su política hemisférica durante el siglo XX:

- En caso de una amenaza externa.

- En caso de desorden económico; y

- En caso de amenaza a la democracia y buena gobernanza. 
Trump está empeñado en recuperar la grandeza de América, con una serie de iniciativas tendentes a devolver los puestos de trabajos al suelo norteamericano, mientras que el poder americano volvería a estar presente a lo largo y ancho del mundo. Ambas políticas afectan a América Latina en su conjunto, y aunque aún no ha delineado una política en relación con la mayoría de los países de América Latina, la generalización de sus opiniones sobre México puede ser extrapolada al resto (Fuentes et al., 2016).

Su política exterior hace hincapié en la necesidad de construir un muro en la frontera sur de los Estados Unidos; su plataforma doméstica, a su vez, hace hincapié en los derechos de la Segunda Enmienda, las grandes reformas fiscales y políticas de inmigración hostiles. La hostilidad de Trump hacia los países de América Latina, específicamente México, vecino de los Estados Unidos, sin duda, representaría un importante obstáculo para la prosperidad del continente si llegara a ganar la presidencia (Fuentes et al., 2016).

\subsubsection{China y la geopolítica de los recursos de América Latina}

Hoy, una nueva configuración de poderes está reformando el orden internacional. Un mundo de una superpotencia y muchas grandes potencias. El nacionalismo y la nación en sí misma lejos de haber sido debilitada por la globalización, ha retornado ahora para vengarse, el nacionalismo étnico ha vuelto con fuerza, pero es más significativo el retorno del nacionalismo de las grandes potencias. En lugar de un nuevo orden mundial, los conflictos de intereses y ambiciones de las grandes potencias están produciendo de nuevo alianzas y contra alianzas, y un elaborado cambio de parejas de baile, que cualquier diplomático del siglo XXI reconocería de forma instantánea (Chen, 2003).

Las relaciones de China con América Latina se han basado en la importación masiva de materias primas. El mayor riesgo se encontraba en una eventual desaceleración de la economía china, que provocara, junto con la reducción en la demanda de recursos energéticos, una recesión que afecta especialmente a las grandes economías del subcontinente: Argentina, Brasil y Venezuela. 
En el 2012 se opinaba que las economías de China y de América Latina y el Caribe -crecerían en los siguientes años entre dos y tres veces más rápido que las economías industrializadas- serían los polos de crecimiento mundial del momento, ya que las economías industrializadas deberán ajustarse a un contexto de menor crecimiento y mayor desempleo (Kuwayana et al., 2012). Nos encontrábamos ante una coyuntura internacional que invita a repensar las estrategias globales y regionales de alianzas, y a conceder una mayor relevancia a los vínculos Sur-Sur en el comercio, la inversión extranjera directa (IED) y la cooperación.

Pero a su vez se alertaba que los países de la región deberían redoblar sus esfuerzos por diversificar sus ventas a China -incorporándoles más valor y conocimiento-, estimular alianzas empresariales, comerciales y tecnológicas con sus pares en ese país, y promover inversiones latinoamericanas en Asia y el Pacífico que faciliten una mayor presencia regional en las cadenas de valor asiáticas, estructuradas en torno a China. Los vínculos comerciales y de inversión entre China y América Latina y el Caribe han seguido expandiéndose.

China se convirtió en un socio comercial clave para la región. Ya que es el primer mercado de destino de las exportaciones del Brasil y Chile, y el segundo del Perú, Cuba y Costa Rica. También es el tercer país entre los principales orígenes de las importaciones de América Latina y el Caribe, con un valor que representa el 13\% del total de las importaciones de la subregión (Kuwayana et al., 2012).

Pero en 2015 la economía mundial continúa sin poder recuperar los niveles de crecimiento que registraba antes de la crisis económica mundial de 2008-2009, siendo la economía estadounidense la más dinámica entre los países desarrollados. China, que ha registrado una de las tasas de crecimiento anuales de su economía más altas del mundo durante el período 2001-2010 (10,5\% en promedio), desde comienzos de 2012, se ha desacelerado, hasta alcanzar un 7,4\% en 2014. En respuesta a la crisis financiera de 2008, China promovió un enorme aumento de la inversión impulsada por la deuda, para compensar el debilitamiento de la demanda externa. Pero el crecimiento en la economía se está desacelerando, y la cantidad de capital necesario para generar ingresos adicionales casi se ha duplicado desde principios de la década de 2000. Es probable que la 
mayor parte de esta inversión sea deficitaria y la economía podría entrar en recesión (Wolf, 2016).

El crecimiento de la región en la última década es fiel reflejo de los vaivenes del contexto económico internacional. Tras el alto crecimiento registrado entre 2003 y 2008 impulsado por un escenario externo favorable, con una economía mundial en expansión, altos precios de los productos básicos, especialmente en América del Sur. La actividad se expandió nuevamente en 2010 y 2011, impulsada por el alto crecimiento de China y las políticas monetarias de los Estados Unidos. Pero a partir de 2012, se registra una acentuada desaceleración del crecimiento en la región (Rosales, 2015).

El crecimiento regional en 2014 fue de apenas 1,1\%, y la CEPAL prevé que en 2015 se desaceleraría levemente. Esta proyección se explica principalmente por el comportamiento esperado de las grandes economías de América del Sur (Argentina, Brasil y República Bolivariana de Venezuela). El valor de las exportaciones de América del Sur probablemente seguirá contrayéndose como resultado de una caída en el volumen de las exportaciones y, particularmente, a los menores precios de sus principales productos básicos de exportación, consecuencia de una menor demanda de importaciones en mercados como China y la Unión Europea (Rosales, 2015).

Si bien la desaceleración de las exportaciones ha afectado a todas las subregiones del continente americano, especialmente a América del Sur, con una dependencia excesiva de las materias primas exportadas a China y la UE. Sería importante, opina Wolf, encontrar un nuevo motor de demanda... Pero no está clara que se vaya a lograr (Rosales, 2015). El resto del mundo está esperando a que EE.UU. proporcione la solución, pero por desgracia esto no ocurrirá. El ajuste de una economía adicta a las burbujas de crédito va a ser difícil.

- La primera tentación es pensar en China como antídoto para liberarse definitivamente de EE.UU.

- La segunda es la relación birregional, tanto la UE como China se enfrentan a una América Latina fragmentada, incapaz de alcanzar consensos en cualquier cuestión de la agenda latinoamericana. 
- La tercera tentación es la de aprovechar el maná chino y el apetito voraz, infinito e inagotable de sus mercados. Ya se ven las consecuencias de la ralentización de la economía china sobre los precios de las commodities y sus repercusiones negativas sobre el crecimiento económico regional.

- La cuarta y última gran tentación latinoamericana es la dependencia crítica de sus exportaciones primarias, especialmente de alimentos. El fenómeno asociado a los incrementos constantes de la demanda asiática en los años de bonanza, fue el de la reprimarización de las exportaciones latinoamericanas (Malamud, 2015).

\subsection{Conclusión}

Si uno ve una representación de la Tierra de noche, lo que destacan son las luces de los espacios donde se concentra la población y la riqueza Norte América, Europa, Japón, Corea. Los BRIC también, pero en menor medida. Quedan los grandes sobrecogedoramente vacíos:

- África subsahariana.

- Gran parte de Sudamérica

- Australia

- Siberia

- El Ártico.

La realidad es que, al fin y al cabo, la visión sistémica no estaba tan desacertada. Si un observador de finales del siglo XIX analizara la realidad actual no se extrañaría: aparece una superpotencia y múltiples grandes potencias que compiten por un poder global, en un marco de incertidumbre característico de una época de transición de liderazgo. Transición desde los EE.UU., posiblemente, de nuevo a los EE.UU., pero ya no como el único hegemón. 